\title{
Temporal Fuzzy Reasoning Spiking Neural P Systems with Real Numbers for Power System Fault Diagnosis
}

\author{
Kang Huang ${ }^{1}$, Tao Wang ${ }^{1}$, Yangyang $\mathrm{He}^{1}$, Gexiang Zhang ${ }^{1 \star}$ and Mario J. \\ Pérez-Jiménez ${ }^{2}$ \\ ${ }^{1}$ School of Electrical Engineering, Southwest Jiaotong University, \\ Chengdu, 610031, P.R. China \\ email: luodanhk@126.com, wangatao2005@163.com, \\ he.yangyang@foxmail.com, zhgxdylan@126.com \\ ${ }^{2}$ Research Group on Natural Computing \\ Department of Computer Science and Artificial Intelligence \\ Universidad de Sevilla, Sevilla, 41012, Spain \\ email: marper@us.es
}

\begin{abstract}
This paper proposes a temporal fuzzy reasoning spiking neural P system with real numbers (rTFRSN P system) and its corresponding fault diagnosis method called FDTSNP to diagnose faults in a power system. The introduction of the rTFRSN P system is to make full use of the temporal order information of alarm messages so as to model candidate fault sections. The presentation of the reasoning algorithm within the framework of an rTFRSN P system tries to obtain confidence levels of candidate faulty sections. Thus, FDTSNP offers an intuitive illustration based on a strictly mathematical expression and a good ability to handle incomplete and uncertain alarm messages with temporal order information. The effectiveness of FDTSNP is verified in various fault cases including single and multiple fault situations with/without incomplete and uncertain alarm messages. Experimental results show that FDTSNP is better than several methods reported in the literature, in terms of the correctness of diagnosis results.
\end{abstract}

Keywords: Membrane computing, spiking neural P system, fuzzy reasoning spiking neural $\mathrm{P}$ system, temporal fuzzy reasoning spiking neural $\mathrm{P}$ system with real numbers, fault diagnosis, power system

\section{Introduction}

Membrane computing, formally introduced by Gh. Păun in [1], is an attractive research field of computer science aiming at abstracting computing models, called membrane systems or P systems, from the structures and functioning of living cells, as well as from the way the cells are organized in tissues or higher order structures. Currently, there are three basic types of $\mathrm{P}$ systems: cell-like $\mathrm{P}$ systems, tissue-like $\mathrm{P}$ systems and neural-like $\mathrm{P}$ systems.

In recent years, the research on neural-like P systems mainly focused on spiking neural P systems (SN P systems), which were introduced in [2]. An SN P system is a

\footnotetext{
${ }^{\star}$ Corresponding author.
} 
kind of distributed and parallel computing models inspired by the neurophysiological behavior of neurons sending electrical impulses (spikes) along axons from presynaptic neurons to postsynaptic neurons. Recently, SN P systems have become a hot topic in membrane computing [3]-[22].

Until now, only a few of investigations focus on the use of SN P systems to solve engineering problems. In [14], a fuzzy reasoning spiking neural $P$ system with real numbers (rFRSN P system) was presented to fulfill fault diagnosis. In [15], an rFRSN $P$ system was used for fault diagnosis of power systems and examples were provided to verify its effectiveness. In [17], adaptive fuzzy spiking neural P systems were applied in fault diagnosis of power transmission networks. In [18], a fuzzy reasoning spiking neural P system with trapezoidal fuzzy numbers (tFRSN P system) was presented to fulfill diagnosis knowledge representation and reasoning, and FDSNP was proposed for fault diagnosis of power systems. In [20], a weighted fuzzy reasoning spiking neural P system (WFRSN P system) was presented for fulfilling fault diagnosis of traction power supply systems of high-speed railways. These aforementioned different kinds of SN P systems, called FRSN P systems, are effective in diagnosing faults of different power systems with uncertainty and incompleteness. However, the studies $[14,15,17,20]$ handled uncertainty and incompleteness by probability statistics where the values were obtained based on the frequency of occurrences from historical data while the study [18] by trapezoidal fuzzy numbers which were based on expertise. As a matter of fact, it is difficult to obtain and process real-time statistical data from huge power networks and expertise is usually influenced by experts' levels. Therefore, how to improve FRSN $P$ systems to handle uncertainty and incompleteness in fault diagnosis of power systems is worth discussing.

There exists a time limit constraint relationship between protective relays and circuit breakers (CBs) and a time cooperation relationship between each grade of protective relays and their corresponding CBs. The temporal order information of alarm messages obtained based on global positioning systems (GPS) can record action sequences of these protective relays and CBs by milliseconds (ms). For each fault in a power system, the temporal order information of alarm messages is obtained immediately and objectively from monitoring equipments. The temporal order information can be used to correct redundant information error by using the temporal order information consistency constraint relationship to filter out wrong alarm messages. Thus, more reliable alarm messages are obtained after the information error correction and can overcome the uncertainty caused by maloperation and operation failure of protection devices. So it is a good way to use the temporal order information of alarm messages to handle uncertainty and incompleteness in fault diagnosis of power systems.

In this study, to make full use of the temporal order information of alarm messages from supervisory control and data acquisition (SCADA) systems, a temporal fuzzy reasoning spiking neural P system with real numbers (rTFRSN P system) is proposed and a fault diagnosis method based on rTFRSN P systems for power systems (FDTSNP, for short) is developed for fault diagnosis of power systems. In FDTSNP, an rTFRSN P systems is introduced to model candidate fault sections, a reasoning algorithm of the rTFRSN P system is presented for fault reasoning to obtain confidence levels of candidate faulty sections and temporal order information consistency constraint relationship is 
used to handle temporal order information of alarm messages as well as judge its validity. To make the rTFRSN P system models quickly be revised when topology structure of power networks have changes, sub-rTFRSN P system models of each sections are considered. Case studies show that FDTSNP is effective in fault diagnosis of power systems in different types of fault cases.

This paper is structured as follows: Section 2 states the problem to solve. The models and reasoning algorithms of rTFRSN P systems are presented in Section 3. Section 4 introduces fault diagnosis method based on P systems (FDTSNP). In Section 5, case studies on fault diagnosis are used to test the effectiveness of FDTSNP. Finally, conclusions are drawn in Section 6.

\section{Reasoning Model-based Methods Considering Temporal Order Information}

When a fault occurs in a power system, electrical quantities change firstly and then protective devices including protective relays and circuit breakers (CBs) operate to isolate this fault. The protective relays consist of main protective relays, first backup protective relays and second backup protective relays. It is worth pointing out that there is not any first backup protective relay for buses [18]. These different kinds of protective relays and their corresponding CBs operate to protect a power system based on certain rules. For details about the operating rules, please see [18].

Thus when a fault occurs, a large number of alarm messages form SCADA systems are poured into dispatchers' consoles in a short period of time. These messages are often incomplete and uncertain due to reasons such as maloperation and refuse operation of protective devices and distortion of communication channel. One way to deal with the uncertainty is to correct the alarm information in the first step of fault diagnosis. So, we improve the framework of fault diagnosis in power systems using reasoning modelbased method in [20] and show it in Fig. 1.

In this study, temporal order information consistency constraint relationship is used to correct the alarm information and then judge the validity of alarm messages. In order to illustrate temporal order information consistency constraint relationship, we first introduce some temporal order concepts as follows.

(1) Time point constraints $T(t)$ [23]

An interval $T(t)=\left[t^{-}, t^{+}\right]$is defined as a constraint of time point, where $t^{-}$ and $t^{+}$are lower and upper bounds of $T(t)$, respectively. $T(t)$ is used to describe the uncertainty of temporal order information of alarm messages. Usually, $t^{-}$and $t^{+}$are set as $95 \%$ and $105 \%$, respectively, i.e., $T(t)=[0.95 t, 1.05 t]$.

(2) Time distance constraints $T\left(t_{i}, t_{j}\right)$ [23]

Time distance $d\left(t_{i}, t_{j}\right)=t_{j}-t_{i}$ represents the time distance between two different alarm messages, where, $t_{i}$ and $t_{j}$ are time points of the messages. An interval $T\left(t_{i}, t_{j}\right)=\left[t_{i j}^{-}, t_{i j}^{+}\right]$is defined as a constraint of time distance, where $t_{i j}^{-}$and $t_{i j}^{+}$ are the lower and upper bounds of $T\left(t_{i}, t_{j}\right)$, respectively. $T\left(t_{i}, t_{j}\right)$ is used to describe the uncertainty of time distance of alarm messages. According to the principle of relay protection, the time distance intervals about different kinds of protective relays and their corresponding CBs are $T(P m, C B s)=[40,60], T(P p, C B s)=[20,40]$, 


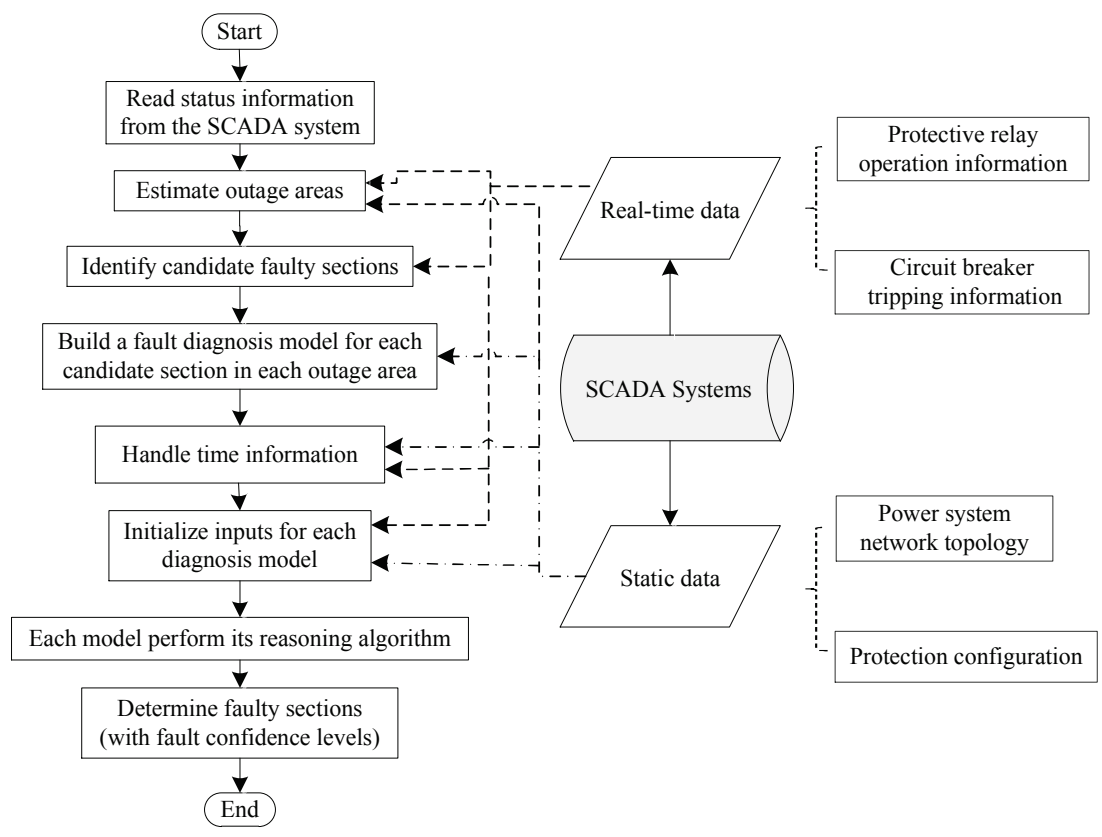

Fig. 1. Power system fault diagnosis framework of reasoning model-based methods considered temporal order information.

$T(P s, C B s)=[40,100]$, where $P m, P p, P s$ represent main protective relays, first backup protective relays and second backup protective relays, respectively.

Next, we describe temporal order information consistency constraint relationship as follows. Temporal order information of alarm messages about related protective devices must satisfy the consistency constraint, as shown in (1) [24].

$$
T\left(t_{A}\right)+T\left(t_{A}, t_{B}\right) \cap T\left(t_{B}\right) \neq \varnothing
$$

where alarm A and alarm B are alarm messages with logical causality; $T\left(t_{A}\right)$ and $T\left(t_{B}\right)$ are operational time point constraints of alarm $\mathrm{A}$ and alarm $\mathrm{B}$, respectively; $T\left(t_{A}, t_{B}\right)$ is a time distance constraints between alarm A and alarm B; the symbol ' + ' is an operation of a time point and a time distance, and means the additions of the two lower time limits and the two upper time limits of $T\left(t_{A}\right)$ and $T\left(t_{A}, t_{B}\right)$, respectively. If temporal order information of alarm A and alarm B fails to satisfy the relationship in (1), then A and $\mathrm{B}$ also fails to satisfy the consistency constraint relationship, which means that alarm messages A and alarm B are invalid.

Besides, we need to illustrate what is corresponding protection set which will be used in the following sections. Fig. 2 is used as a simple example to describe the causality between protective relays and CBs. According to the principle of relay protection, we know that circuit breakers $C B_{i j}$ and $C B_{j i}$ on line $L_{i j}$ has causal relationship with protective relays. In this study, these protective relays are put into two sets, i.e., $C_{i j}$ and 


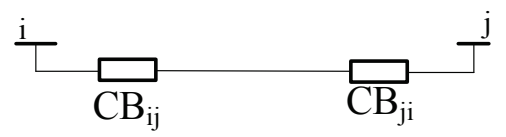

Fig. 2. A sketch map of protective relays and CBs.

$C_{j i}$, where $C_{i j}$ and $C_{j i}$ represent protective relays corresponding to $C B_{i j}$ and $C B_{j i}$, respectively.

$$
\begin{gathered}
C_{i j}=\left\{B_{i m}, L_{i j S m}, L_{i j S p}, L_{i j S s}\right\} \\
C_{j i}=\left\{B_{j m}, L_{i j R m}, L_{i j R p}, L_{i j R s}\right\}
\end{gathered}
$$

\section{3 rTFRSN P Systems}

\subsection{Definitions}

Definition 1: An rTFRSN P system of $m \geq 1$ is a tuple $\Pi=\left(O, \sigma_{1}, \ldots, \sigma_{m}\right.$, syn, in, out), where:

(1) $O=\{a\}$ is a singleton alphabet ( $a$ is called spike);

(2) $\sigma_{1}, \ldots, \sigma_{m}$ are neurons. For proposition neurons, they are with the form $\sigma_{i}=$ $\left(\theta_{i}, t_{i}, r_{i}\right), 1 \leq i \leq s$; for rule neurons, they are with the form $\sigma_{i}=\left(\delta_{i}, c_{i}, r_{i}\right), 1 \leq$ $i \leq t, s+t=m$, where:

(a) $\theta_{i}$ is a real number in $[0,1]$ representing the potential value of spikes (i.e. value of electrical impulses) contained in proposition neuron $\sigma_{i}$;

(b) $t_{i}$ is a real number either 0 or 1 representing the state of proposition neuron $\sigma_{i}$. If $t_{i}=1$, then the alarm message associated with $\sigma_{i}$ is valid; otherwise, the alarm message associated with $\sigma_{i}$ is invalid;

(c) $\delta_{i}$ is a real number in $[0,1]$ representing the potential value of spikes (i.e. value of electrical impulses) contained in rule neuron $\sigma_{i}$;

(d) $c_{i}$ is a real number in $[0,1]$ representing the truth value associated with rule neuron $\sigma_{i}$ and is identical with the certainty factor of the fuzzy production rules corresponding to rule neuron $\sigma_{i}$;

(e) For both proposition neurons and rule neurons, $r_{i}$ represents a firing (spiking) rule contained in neuron $\sigma_{i}$ with the form $E / a^{\theta} \rightarrow a^{\beta}$, where $\theta$ and $\beta$ are real numbers in $[0,1], E=\left\{a^{n}\right\}$ is the firing condition. The firing condition means that if and only if neuron $\sigma_{i}$ receives at least $n$ spikes, then the firing rule contained in the neuron can be applied, otherwise, the firing rule cannot be applied;

(3) syn $\subseteq\{1,2, \ldots, m\} \times\{1,2, \ldots, m\}$ with $i \neq j$ for all $(i, j) \in$ syn $, 1 \leq i, j \leq m$, is a directed graph of synapses between the linked neurons;

(4) in, out $\subseteq\{1,2, \ldots, m\}$ indicate the input neuron set and the output neuron set of $\Pi$, respectively. 
An rTFRSN P system is an extension of SN P systems. (1) The definition of neurons are extended. The rTFRSN P systems consist of two kinds of neurons: proposition neurons and rule neurons, where rule neurons contain two subcategories: and and or. (2) The pulse value $\theta_{i}$ contained in each proposition neuron or the pulse value $\delta_{i}$ contained in each rule neuron is a real number in $[0,1]$ representing potential value of spikes contained in this neuron instead of the number of spikes in SN P systems. (3) Each neuron $\sigma_{i}$ is associated with either a proposition or a fuzzy production rule. For a proposition neuron $\sigma_{i}$, the real number $t_{i}$ represents the state of this proposition neuron and is used to determine whether proposition neuron $\sigma_{i}$ is valid or not. If $t_{i}=1$, then the alarm message associated with $\sigma_{i}$ is valid and this means that the protective device associated with this alarm message operates correctly; otherwise, the alarm message associated with $\sigma_{i}$ is invalid and this means that the protective device associated with this alarm message maloperates. For a rule neuron $\sigma_{i}$, the real number $t_{i} \in[0,1]$ represents the certainty factor $(\mathrm{CF})$ of the fuzzy production rule associated with $\sigma_{i}$. (4) Each neuron contains only one firing (spiking) rule of the form $E / a^{\theta} \rightarrow a^{\beta}$. When the firing condition of one neuron is satisfied, the firing rule is applied, which means that the potential value $\theta$ is consumed and then this neuron produces a new spike with potential value of $\beta$. These different types of neurons aforementioned handle the potential values $\theta$ and $\beta$ in different ways. In this study, $t_{i}$ is used to determine whether proposition neuron $\sigma_{i}$ is valid and the value of $t_{i}$ itself is not used in a computing process. Therefore, the definitions of neurons (and and or rule neurons) and ways of handling potential values $\theta$ and $\beta$ are the same with those in [14]. Thus, we will not describe them again here (see [14] for more details). If the firing condition of one neuron is satisfied, then the potential value of the spikes received by this neuron is updated via logical and or or operators. (5) Time delay is ignored in rTFRSN P systems, thus all neurons are always open.

\subsection{Reasoning algorithm}

In order to present a reasoning algorithm for rTFRSN P systems, we first introduce some parameter vectors and matrices as follows.

(1) $\boldsymbol{\theta}=\left(\theta_{1}, \ldots, \theta_{s}\right)^{T}$ is a real truth value vector of the $s$ proposition neurons, where $\theta_{i}(1 \leq i \leq s)$ is a real number in $[0,1]$ representing the potential value contained in the $i$ th proposition neuron. If there is not any spike contained in a proposition neuron, its potential value is 0 .

(2) $\boldsymbol{\delta}=\left(\delta_{1}, \ldots, \delta_{t}\right)^{T}$ is a real truth value vector of the $t$ rule neurons, where $\delta_{j}$ $(1 \leq j \leq t)$ is a real number $[0,1]$ representing the potential value contained in the $j$ th rule neuron. If there is not any spike contained in a rule neuron, its potential value is 0 .

(3) $\boldsymbol{C}=\operatorname{diag}\left(c_{1}, \ldots, c_{t}\right)$ is a diagonal matrix, where $c_{j}(1 \leq j \leq t)$ is a real number in $[0,1]$ representing the certainty factor of the $j$ th fuzzy production rule.

4) $\boldsymbol{D}_{1}=\left(d_{i j}\right)_{s \times t}$ is a synaptic matrix representing the directed connection from proposition neurons to general rule neurons. If there is a directed arc (synapse) from the proposition neuron $\sigma_{i}$ to the general rule neuron $\sigma_{j}$, then $d_{i j}=1$, otherwise, $d_{i j}=0$.

5) $\boldsymbol{D}_{2}=\left(d_{i j}\right)_{s \times t}$ is a synaptic matrix representing the directed connection from proposition neurons to and rule neurons. If there is a directed arc (synapse) from the proposition neuron $\sigma_{i}$ to the and rule neuron $\sigma_{j}$, then $d_{i j}=1$, otherwise, $d_{i j}=0$. 
6) $\boldsymbol{D}_{3}=\left(d_{i j}\right)_{s \times t}$ is a synaptic matrix representing the directed connection from proposition neurons to or rule neurons. If there is a directed arc (synapse) from the proposition neuron $\sigma_{i}$ to the or rule neuron $\sigma_{j}$, then $d_{i j}=1$, otherwise, $d_{i j}=0$.

7) $\boldsymbol{E}=\left(e_{j i}\right)_{t \times s}$ is a synaptic matrix representing the directed connection from rule neurons to proposition neurons. If there is a directed arc (synapse) from the rule neuron $\sigma_{j}$ to the proposition neuron $\sigma_{i}$, then $e_{j i}=1$, otherwise, $e_{j i}=0$.

Subsequently, we introduce some multiplication operations as follows.

(1) $\otimes: D^{T} \otimes \theta=\left(\bar{d}_{1}, \ldots, \bar{d}_{t}\right)^{T}$, where $\bar{d}_{j}=d_{1 j} * \theta_{1}+\ldots+d_{s j} * \theta_{s}$, for $j=1, \ldots, t$.

(2) $\oplus: D^{T} \oplus \theta=\left(\bar{d}_{1}, \ldots, \bar{d}_{t}\right)^{T}$, where $\bar{d}_{j}=\min \left\{d_{1 j} * \theta_{1}, \ldots, d_{s j} * \theta_{s}\right\}$, for $j=1, \ldots, t$.

(3) $\odot: D^{T} \odot \theta=\left(\bar{d}_{1}, \ldots, \bar{d}_{t}\right)^{T}$, where $\bar{d}_{j}=\max \left\{d_{1 j} * \theta_{1}, \ldots, d_{s j} * \theta_{s}\right\}$, for $j=1, \ldots, t$.

Next, we list the pseudocode of reasoning algorithm for rTFRSN P systems.

INPUT: The fuzzy truth values of the propositions corresponding to the input proposition neurons.

OUTPUT: The fuzzy truth values of the propositions corresponding to the output proposition neurons.

Step 1): Let $g=0$ be the reasoning step;

Step 2): Set initial values of $\boldsymbol{D}_{1}, \boldsymbol{D}_{2}, \boldsymbol{D}_{3}, \boldsymbol{E}, \boldsymbol{C}$ and the termination condition $\boldsymbol{0}_{1}=$ $\left(\text { unknown, }{ }_{(}^{(t)} \text {., unknown }\right)^{T}$. The initial values of $\boldsymbol{\theta}$ and $\boldsymbol{\delta}$ are set to $\boldsymbol{\theta}_{g}=\left(\theta_{1 g}, \theta_{2 g}\right.$, $\left.\ldots, \theta_{s g}\right)$ and $\boldsymbol{\delta}_{g}=\left(\delta_{1 g}, \delta_{2 g}, \ldots, \delta_{t g}\right)$, respectively;

Step 3): $g$ is increased by one;

Step 4): The firing condition of each input neuron $(g=1)$ or each proposition neuron $(g>1)$ is evaluated. If the condition $E=a^{s}$ is satisfied and there is a postsynaptic rule neuron, the neuron fires and transmits a spike to the next rule neuron;

Step 5): Compute the fuzzy truth value vector $\boldsymbol{\delta}_{g}$ according to (4);

$$
\boldsymbol{\delta}_{g}=\left(\mathbf{D}_{1}^{T} \otimes \boldsymbol{\theta}_{g-1}\right)+\left(\mathbf{D}_{2}^{T} \oplus \boldsymbol{\theta}_{g-1}\right)+\left(\mathbf{D}_{3}^{T} \odot \boldsymbol{\theta}_{g-1}\right)
$$

Step 6) If $\boldsymbol{\delta}_{g}=\mathbf{0}_{1}$, the algorithm halts and outputs the reasoning results;

Step 7): Evaluate the firing condition of each rule neuron. If the condition $E=a^{s}$ is satisfied, the rule neuron fires and transmits a spike to the next proposition neuron; Step 8): Compute the fuzzy truth value vector $\boldsymbol{\theta}_{g}$ according to (5). Go to Step 3.

$$
\boldsymbol{\theta}_{\boldsymbol{g}}=\mathbf{E}^{T} \odot\left(\mathbf{C} \otimes \boldsymbol{\delta}_{\boldsymbol{g}}\right)
$$

\section{Fault Diagnosis Method Based on rTFRSN P Systems}

\subsection{Fault diagnosis models based on rTFRSN P systems}

In this study, fault diagnosis of faulty sections are considered according to the statuses of protective relays and circuit breakers (CBs) because they are normally read from a power SCADA system. The protective relays consist of main protective relays, first backup protective relays and second backup protective relays, which are represented by $m, p, s$, respectively. For transmission lines, there are two types of protective relays: 


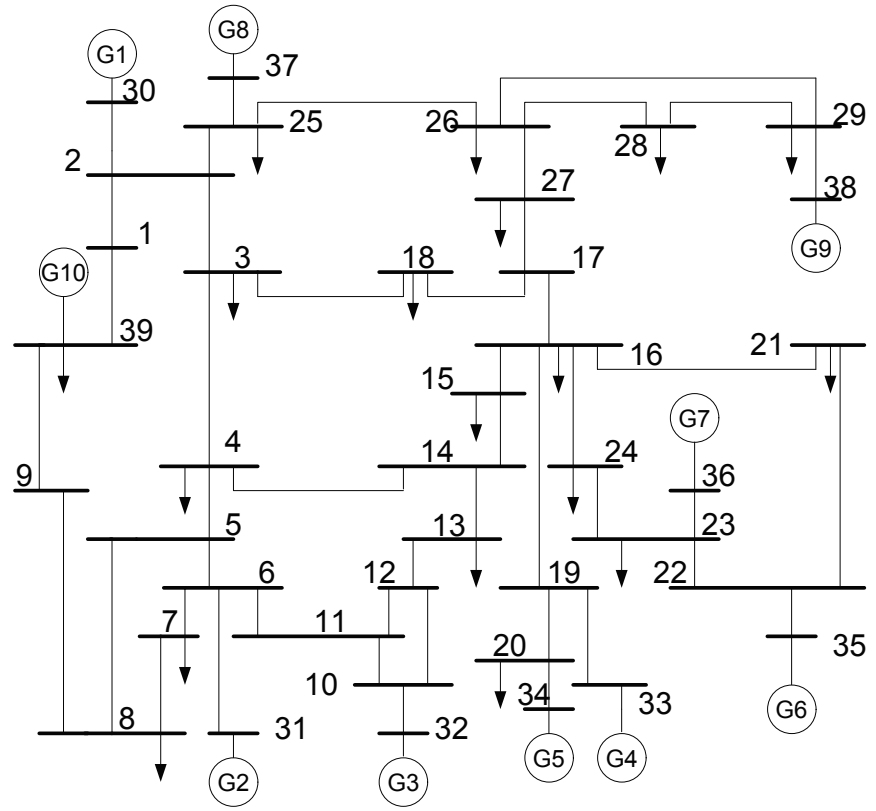

Fig. 3. Topological diagram of IEEE 10 Generator 39 Bus System.

sending end protective relays and receiving end protective relays, which are represented by $S$ and $R$, respectively. It is worth pointing out that there is not any first backup protection devices for buses. Fig. 3 shows an IEEE 10 Generator 39 Bus System, which is used to illustrate how to build rTFRSN P system fault diagnosis models.

First, bus $B_{04}$ in Fig. 3 is used to describe model building of buses, where the fault confidence level of bus $B_{04}$ is the maximal value of outputs of the three sub-rTFRSN P systems. We can see that $B_{04}$ connects with lines $L_{0304}, L_{0405}, L_{0414}$. When $B_{04}$ has a fault, the main protective relay $B_{04 m}$ of $B_{04}$ will act to trip its corresponding CBs, i.e., $C B_{0304}, C B_{0405}$ and $C B_{0414}$, to protect this bus. If $B_{04 m}$ does not operate or its associated $\mathrm{CBs}$ do not trip, then first backup protective relays of bus $B_{04}$ will act to trip their associated CBs. Otherwise, this fault will spread to the adjacent lines of bus $B_{04}$. For example, if $C B_{0414}$ does not trip, then second backup protective relay $L_{0304 S s}$ will act to trip $C B_{0403}$ to isolate the fault section. Likewise, if $C B_{0405}$ does not trip, then second backup protective relay $L_{0405 R s}$ will act to trip $C B_{0504}$; if $C B_{0414}$ does not trip, then second backup protective relay $L_{0414 R s}$ will act to trip $C B_{1404}$. Thus, the fault production rules of bus $B_{04}$ are described as follows (let us note that the number of fault fuzzy production rules of a bus is identical with the number of its adjacent lines).

$R_{1}$ : IF ( $B_{04 m}$ operates and $C B_{0414}$ trips $) O R\left(L_{0414 R s}\right.$ operates and $C B_{1404}$ trips while $C B_{0414}$ does not trip) $T H E N B_{04}$ faults $(C F=0.95)$

$R_{2}$ : IF ( $B_{04 m}$ operates and $C B_{0403}$ trips $) O R\left(L_{0304 S s}\right.$ operates and $C B_{0304}$ trips while $C B_{0403}$ does not trip) $T H E N B_{04}$ faults $(C F=0.95)$ 
$R_{3}$ : IF ( $B_{04 m}$ operates and $C B_{0405}$ trips $)$ OR $\left(L_{0405 R s}\right.$ operates and $C B_{0504}$ trips while $C B_{0405}$ does not trip) THEN $B_{04}$ faults $(C F=0.95)$

Therefore, fault diagnosis models based on rTFRSN P systems for bus $B_{04}$ are built according to these three fault production rules shown in Fig. 4 . The corresponding rTFRSN P system for bus $B_{04}$ is defined as follows:

$$
\Pi_{1}=\left(O, \sigma_{1}, \sigma_{2}, \ldots, \sigma_{10}, \text { syn }, \text { in }, \text { out }\right)
$$

where

1) $O=\{a\}$ is the singleton alphabet ( $a$ is called spike);

2) $\sigma_{1}, \sigma_{2}, \ldots, \sigma_{7}$ are proposition neurons corresponding to the propositions with fuzzy truth values $\theta_{1}, \theta_{2}, \ldots, \theta_{7}$;

3) $\sigma_{8}, \sigma_{9}, \sigma_{10}$ are rule neurons, where $\sigma_{8}, \sigma_{9}$ are and rule neurons, $\sigma_{10}$ are or rule neurons;

4) syn $=\{(1,8),(2,8),(2,9),(3,9),(4,9),(5,10),(6,10),(8,5),(9,6),(10,7)\}$;

5) in $=\left\{\sigma_{1}, \sigma_{2}, \sigma_{3}, \sigma_{4}\right\}$, out $=\left\{\sigma_{7}\right\}$.

It is worth pointing out that there are assistant arcs in this figure. For example, in Fig. 4 (a), there is an assistant arc from $\sigma_{2}$ to $\sigma_{9}$. It means that if $C B_{0414}$ trips, then the operation information about $L_{0414 R s}$ and $C B_{1404}$ is invalid. Likewise, the meaning of assistant arcs in Fig. 4 (b) and (c) is similar.

Then, transmission line $L_{0939}$ in Fig. 3 is used to describe model building of transmission lines, where the fault confidence level of line $L_{0939}$ is the maximal value of outputs of the two sub-rTFRSN P systems. Fault fuzzy production rules of transmission line $L_{0939}$ are described as follows.

$R_{1}: I F\left(L_{0939 S m}\right.$ operates and $C B_{0939}$ trips $) O R\left(L_{0939 S p}\right.$ operates and $C B_{0939}$ trips $O R\left(L_{0809 S s}\right.$ operates and $C B_{0809}$ trips $\left.)\right)$ while $C B_{0939}$ does not trip) THEN $L_{0939}$ faults $(C F=0.95)$

$R_{2}: I F\left(L_{0939 R m}\right.$ operates and $C B_{0939}$ trips $)$ OR $\left(L_{0939 R p}\right.$ operates and $C B_{0939}$ trips $O R\left(L_{0139 S s}\right.$ operates and $C B_{0139}$ trips $\left.)\right)$ while $C B_{3909}$ does nottrip) THEN $L_{0939}$ faults $(C F=0.95)$

From Fig. 3, we can see that $L_{0939}$ connects with lines $L_{0139}$ and $L_{0809}$. When $L_{0939}$ has a fault, the main protective relays, $L_{0939 S m}$ and $L_{0939 R m}$, of $L_{0939}$ will act to trip $L_{0939}$ and $L_{3909}$ to protect this line. If main protective relays do not operate or their associated CBs do not trip, then first backup protective relays, $L_{0939 S p}$ and $L_{0939 R p}$ of line $L_{0939}$ will act to trip their associated CBs. Otherwise, this fault will spread to adjacent lines. For example, if $C B_{0939}$ does not trip , then second backup protective relay $L_{0809 S s}$ will act to trip $C B_{0809}$ to isolate the fault section. Likewise, if $C B_{3909}$ does not trip, then second backup protective relay $L_{0139 S s}$ will act to trip $C B_{0139}$. For a transmission line, a fault can spread to its sending terminal and receiving terminal. Thus, the number of fault fuzzy production rules for a line is always equal to two.

Therefore, fault diagnosis models based on rTFRSN P systems for transmission line $L_{0939}$ are built according to two fault fuzzy production rules and are shown in Fig. 5. It is worth pointing out that there are assistant arcs in this figure. For example, in Fig. 


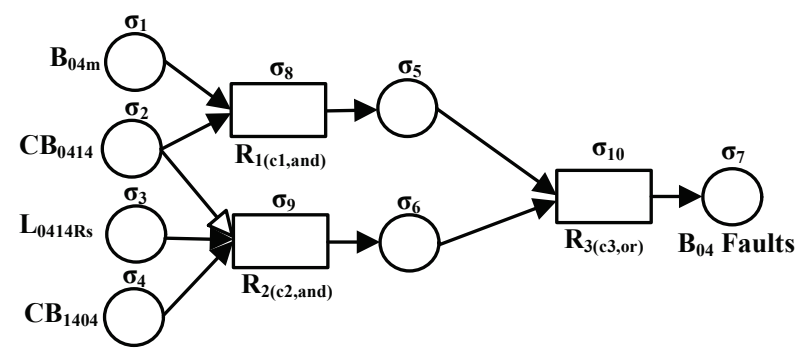

(a)

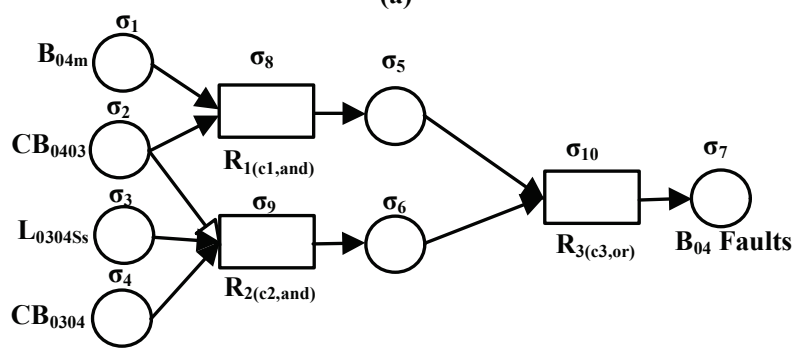

(b)

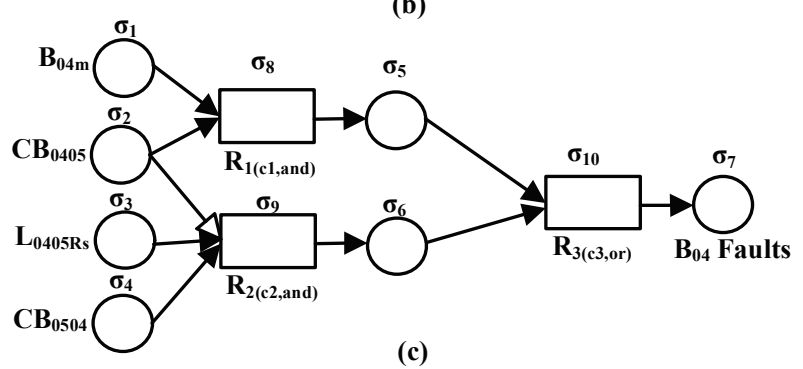

Fig. 4. Fault diagnosis models based on rTFRSN P systems for bus $B_{04}$. (a) Rule 1; (b) Rule 2; (c) Rule 3.

5 (a), there is an assistant arc from $\sigma_{2}$ to $\sigma_{12}$. It means that if $C B_{0309}$ trips, then the operation information about $L_{0809 S s}$ and $C B_{0809}$ is invalid. Likewise, the meaning of the assistant arc in Fig. 5 (b) is similar.

\subsection{FDTSNP}

This subsection summarizes the fault diagnosis method called FDTSPNP, as follows.

Step 1: Read operation messages about protective relays and/or CBs and temporal order information of these protective devices in a power transmission network from the SCADA system.

Step 2: Search for outage areas and find out candidate faulty sections using network topology analysis [18].

Step 3: If there is only one section in the outage areas found in Step 2, this section is the faulty one and the algorithm stops, otherwise, a fault diagnosis model based on 


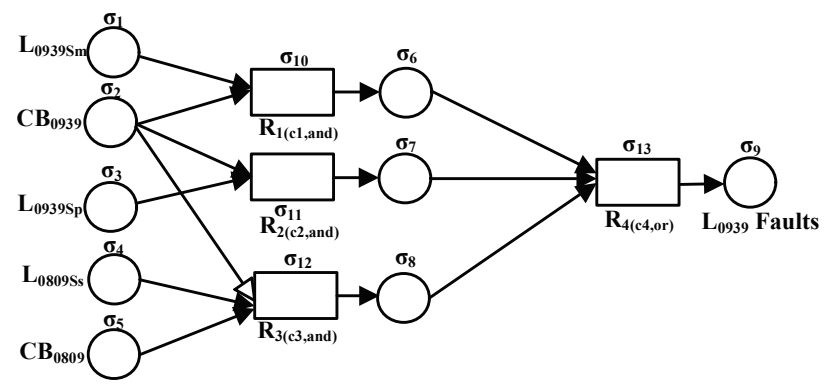

(a)

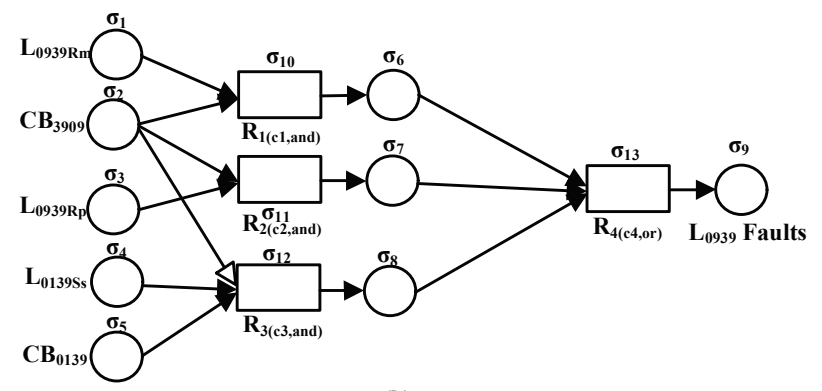

(b)

Fig. 5. Fault diagnosis models based on rTFRSN P systems for lien $L_{0939}$. (a) Rule 1; (b) Rule 2.

an rTFRSN P system is built for each section. The model-building process is described as follows. A section in the passive network is chosen randomly. According to the relay protections of the section, we design fault fuzzy production rules and then determine proposition and rule neurons and create their linking relationship to obtain the rTFRSN $\mathrm{P}$ system. The certainty factor of each rule is empirically set. According to Table 1, we set confidence levels for main protections, first backup protections, second backup protections and their CBs. Then a one-to-one relationship between the fuzzy truth value of each input neuron and the confidence level of each protection is established to obtain the initial values of the model.

Step 4: Handle temporal order information of protective devices in alarm messages to acquire initialed parameters of each rTFRSN P system model built in Step 3, i.e., parameters of input neurons of each rTFRSN P system model. The temporal order information handling process is described as follows:

(i) Classify alarm messages from SCADA systems into 2 types: information about protective relays and CBs. Put these two types of information into two sets $M_{1}$ and $N_{1}$, respectively. For example, $M_{1}=\left\{P_{1}, \ldots, P_{n}\right\}, N_{1}=\left\{C B_{1}, \ldots, C B_{k}\right\}$, where $n$ is the number of protective relays and $k$ is the number of CBs in the obtained SCADA data.

(ii) Obtain protective relay sets $A_{1}, \ldots, A_{k}$ according to protective logic relationship between protective relays and CBs, where $A_{1}, \ldots, A_{k}$ are logical related with CBs in $N_{1}$. 
Table 1. Operation and non-operation confidence levels of the protective devices

\begin{tabular}{|c|c|c|c|c|c|c|c|c|c|c|c|c|}
\hline \multirow{3}{*}{ Sections } & \multicolumn{6}{|c|}{ Protective devices (operated) } & \multicolumn{6}{|c|}{ Protective devices (non-operated) } \\
\hline & \multicolumn{2}{|c|}{ Main } & \multicolumn{2}{|c|}{$\begin{array}{l}\text { Primary } \\
\text { backup }\end{array}$} & \multicolumn{2}{|c|}{$\begin{array}{l}\text { Remote } \\
\text { backup }\end{array}$} & \multicolumn{2}{|c|}{ Main } & \multicolumn{2}{|c|}{$\begin{array}{l}\text { Primary } \\
\text { backup }\end{array}$} & \multicolumn{2}{|c|}{$\begin{array}{l}\text { Remote } \\
\text { backup }\end{array}$} \\
\hline & Relays & $\mathrm{CBs}$ & Relay & $\mathrm{S} C B s$ & Relay & $\mathrm{CBs}$ & Relay & $\mathrm{CBs}$ & Relays & $\mathrm{CBs}$ & Relays & $\mathrm{CBs}$ \\
\hline$F L$ & 0.9 & 0.85 & 0.8 & 0.75 & 0.7 & 0.65 & 0.2 & 0.2 & 0.2 & 0.2 & 0.2 & 0.2 \\
\hline$B$ & 0.9 & 0.85 & - & - & 0.7 & 0.65 & 0.2 & 0.2 & - & - & 0.2 & 0.2 \\
\hline$T$ & 0.9 & 0.85 & 0.8 & 0.75 & 0.7 & 0.65 & 0.2 & 0.2 & 0.2 & 0.2 & 0.2 & 0.2 \\
\hline
\end{tabular}

(iii) Obtain protective relay sets $Q_{j}(1 \leq j \leq k)$, where $\left.Q_{j}=M_{1} \cap A_{j}, 1 \leq j \leq k\right)$. If $Q_{j}=\varnothing$, then status information of $C B_{j}$ in $N_{1}$ is invalid. Set $N_{2}$ is built according to $N_{2}=\left\{C B_{j} \mid Q_{j}=\varnothing\right\}$ and remainder CBs are put into set $N$, where CBs in $N_{2}$ have no logical relation with protective relays in SCADA data and $N=N_{1}-N_{2}$.

(iv) Obtain protective relay sets $M_{2}$, where $M_{2}=M_{1}-\left(Q_{1} \cup \cdots \cup Q_{k}\right)$, protective relays in $M_{2}$ have no logical relation with CBs. There are two kinds of protective relays information in set $M_{2}$. One is that protective relays maloperate, and the other one is that CBs associated with that protective relays fail to trip.

(v) Assume that there are still $n \mathrm{CBs}$ in $N, N=C B_{1}, \ldots, C B_{n}$. Build set $C_{i}=$ $C B_{i}(1 \leq i \leq n)$, that is $N=C_{1} \cup \ldots \cup C_{n}$. For $C B_{i}$ in $C_{i}$, it corresponding protective relay set $Q_{i}$ is $Q_{i}=M_{1} \cap A_{i}$. Determine whether protective relay $P$ in set $Q_{i},(i \leq i \leq n)$ and $C B_{i},(i \leq j \leq k)$ in set $C_{i}$ satisfy temporal order information consistency constraint relationship or not according to $T\left(t_{A}\right)+T\left(t_{A}, t_{B}\right) \cap T\left(t_{B}\right) \neq \varnothing$. The results are $F_{C B i}=\left\{C B_{i} \mid\left(T\left(t_{p}\right)+t\left(P, C B_{i}\right)\right) \cap T\left(t_{C B_{i}}\right)=\varnothing, P \in Q_{i}, C B_{i} \in\right.$ $\left.C_{i}\right\}, T_{C B i}=\left\{C B_{i} \mid\left(T\left(t_{p}\right)+t(P, C B i)\right) \cap T\left(t_{C B i}\right) \neq \varnothing, P \in Q_{i}, C B_{i} \in C_{i}\right\}$, $T_{i}=T_{C B i} \cup Q_{i}$. Finally, $T=T_{1} \cup \ldots \cup T_{n}, F=F_{C B 1} \cup \ldots \cup F_{C B n}$.

(vi) Search set $M_{2}$ to find out main protective relays of lines, and put them into set $M_{3}$. If there exists the same type of alarm messages in set $M_{3}$ as those in set $T$, we assume that these messages are valid and put them in set $M_{4}$. In this study, we consider protective relays of lines on sending terminal and receive terminal as the same type. For example, in Fig. 3 , protective relays $L_{0414 S m}$ and $L_{0414 R m}$ are of the same type. That is to say, if $L_{0414 S m}$ is valid, then $L_{0414 R m}$ is also valid. Likewise, if $L_{0414 R m}$ is valid, then $L_{014 S m}$ is also valid.

(vii) The invalid alarm messages are in $L=N_{2} \cup\left(M_{2}-M_{4}\right) \cup F$ and the valid ones are in set $H=T \cup M_{4}$.

Step 5: Perform reasoning algorithm to get the fault confidence level of each section. Initial values of proposition neurons in each rTFRSN P system model are set according to the SCADA data and $T=\left(t_{1}, \ldots, t_{m}\right)$ obtained in the last step, where if $t_{i}=1$, then the alarm information is valid and the pulse value in the $i$ th proposition neuron is set according to the operated protective devices in Table 1; otherwise, it is invalid and the pulse value in the $i$ th proposition neuron is set according to the non-operated protective devices in Table 1. 
Step 6: If the confidence level $\theta$ of a section satisfies the condition $\theta \geq 0.5$, the section is faulty, otherwise, the section is not faulty. And last, we evaluate the operation of protective relays and/or CBs.

\section{Case Studies}

In this section, five cases of the IEEE 39 Bus System shown in Fig. 3 are considered as examples to test the effectiveness and superiority of FDTSNP described in subsection 4.2. What is more, we take case 1 as an example to illustrate the steps of FDTSNP.

Case 1: bus $B_{14}$ has a fault.

Step 1: Status information is obtained from the SCADA system. Operated relays: $\left(B_{14 m}, 20 \mathrm{~ms}\right),\left(L_{0414 S s}, 750 \mathrm{~ms}\right)$ and $\left(L_{1415 R s}, 371 \mathrm{~ms}\right)$. Tripped CBs: $\left(C B_{1415}, 73 \mathrm{~ms}\right)$, $\left(C B_{1413}, 81 \mathrm{~ms}\right),\left(C B_{0414}, 87 \mathrm{~ms}\right)$.

Step 2: Candidate faulty sections, bus $B_{14}$ and line $L_{0414}$, are obtained by using topology analysis.

Step 3: Fault diagnosis models based on rTFRSN P systems for bus $B_{14}$ and line $L_{0414}$ are built, as shown in Fig. 6 and Fig. 7, respectively.

Step 4: Temporal order information of protective devices in alarm messages is handled to acquire initialed parameters of rTFRSN P system models for bus $B_{14}$ and line $L_{0414}$.

(1) Construct sets $M_{1}$ and $N_{1}$. In this case, $M_{1}=\left\{B_{14 m}, L_{0414 S s}, L_{1415 R s}\right\}$, $N_{1}=\left\{C B_{1415}, C B_{1413}, C B_{0414}\right\}$.

(2) Construct set $A_{1}, A_{2}$ and $A_{3}$. In this case, $A_{1}=\left\{B_{14 m}, L_{1415 S m}, L_{1415 S p}, L_{1415 S s}\right\}$, $A_{2}=\left\{B_{14 m}, L_{1314 R m}, L_{1314 R p}, L_{1314 R s}\right\}, A_{3}=\left\{B_{04 m}, L_{0414 S m}, L_{0414 S p}\right.$, $\left.L_{0414 S s}\right\}$.

(3) Construct sets $Q_{i}, 1 \leq i \leq 3$ and $N_{2}$. In this case, $Q_{1}=M_{1} \cap A_{1}=\left\{B_{14 m}\right\}$, $Q_{2}=M_{1} \cap A_{2}=\left\{B_{14 m}\right\}, Q_{3}=M_{1} \cap A_{3}=\left\{L_{0414 S s}\right\}, N_{2}=\varnothing$.

(4) Construct set $M_{2}$. In this case, $M_{2}=M_{1}-Q_{1} \cup Q_{2} \cup Q_{3}=\left\{L_{1415 R s}\right\}$.

(5) Construct set $F$. In this case, $N=N_{1}=\left\{C B_{1415}, C B_{1413}, C B_{0414}\right\}, C_{1}=$ $\left\{C B_{1415}\right\}, C_{2}=\left\{C B_{1413}\right\}, C_{3}=\left\{C B_{0414}\right\}, Q_{1}=\left\{B_{14 m}\right\}, Q_{2}=\left\{B_{14 m}\right\}, Q_{3}=$ $\left\{L_{0414 S s}\right\}$. Using temporal order information consistency constraint relationship, we get that $F_{C B 1}=\varnothing, T_{C B 1}=\left\{C B_{1415}\right\}$. Likewise, $F_{C B 2}=\varnothing, T_{C B 2}=\left\{C B_{1413}\right\}$, $F_{C B 3}=\left\{C B_{0414}\right\}, T_{C B 3}=\varnothing$. Thus, $T=T_{C B 1} \cup T_{C B 2} \cup T_{C B 3} \cup Q_{1} \cup Q_{2} \cup$ $\left.Q_{3}\right\}=\left\{C B_{1415}, C B_{1413}, B_{14 m}, L_{0414 S s}\right\}, F=F_{C B 1} \cup F_{C B 2} \cup F_{C B 3}=\left\{C B_{0414}\right\}$.

(6) There is not any main protections of line in set $M_{2}$. Thus, $M_{3}=M_{4}=\varnothing$

(7) Find invalid alarm message sets: $L=N_{2} \cup\left(M_{2}-M_{4}\right) \cup F=\left\{L_{1415 R s}, C B_{0414}\right\}$, and valid alarm messages set: $H=T \cup M_{4}=\left\{C B_{1415}, C B_{1413}, B_{14 m}, L_{0414 S s}\right\}$.

Step 5: Perform reasoning algorithm to get the confidence levels of candidate faulty sections mentioned above. For bus $B_{14}$, according to the temporal order information $T_{i}, 1 \leq i \leq 3$, of proposition neurons in Fig. 6 (a), (b) and (c) are [1, 0, 1, 0, 0, 0, $0],[1,1,0,0,0,0,0]$ and $[1,1,0,0,0,0,0]$, respectively. Therefore, according to $T_{i}, 1 \leq i \leq 3$, and Table 1 , we get the initial parameter matrices: $\boldsymbol{\theta}_{\mathbf{0 a}}=\left[\begin{array}{llll}0.9 & 0.2 & 0.8 & 0.2\end{array}\right.$

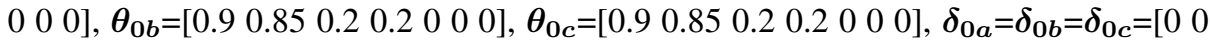

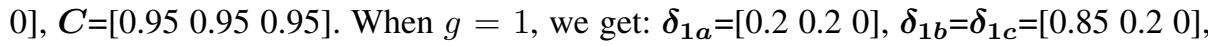

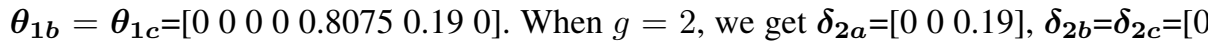




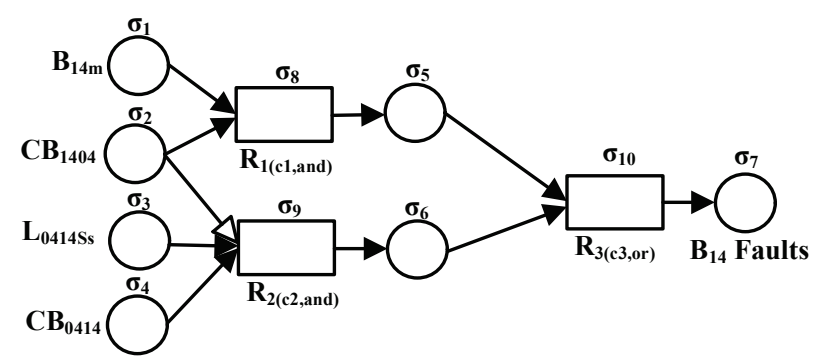

(a)

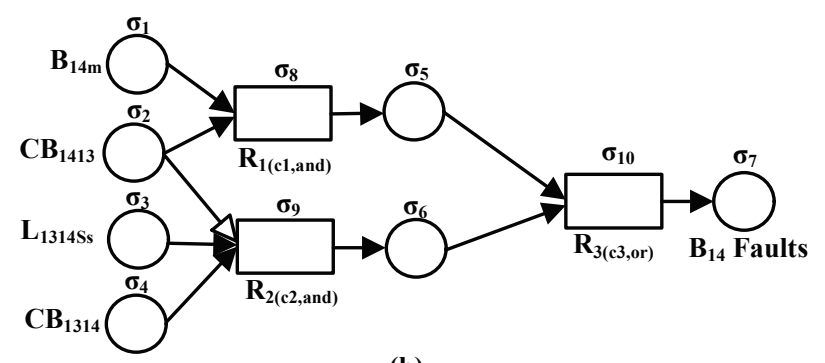

(b)

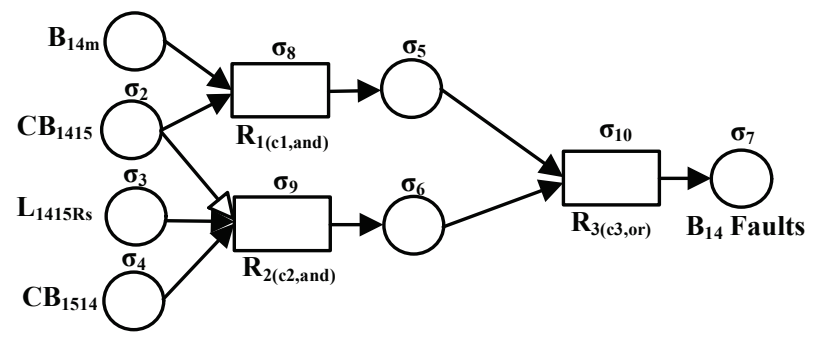

(c)

Fig. 6. Fault diagnosis models based on rTFRSN P systems for bus $B_{14}$.

$\left.\begin{array}{lll}0 & 0.8075\end{array}\right], \boldsymbol{\theta}_{\mathbf{2} \boldsymbol{b}}=\left[\begin{array}{lllllll}0 & 0 & 0 & 0 & 0 & 0 & 0.1805\end{array}\right], \boldsymbol{\theta}_{\mathbf{2 c}}=\left[\begin{array}{lllllll}0 & 0 & 0 & 0 & 0 & 0 & 0.1805\end{array}\right]$. When $g=3$, we get: $\delta_{3 a}=\delta_{3 b}=\delta_{0 c}=\left[\begin{array}{lll}0 & 0 & 0\end{array}\right]$. Thus, the termination condition is satisfied and the reasoning process ends. We obtain the reasoning results, i.e., the fuzzy truth values $0.1805,0.767$, 0.767 from output neuron $\sigma_{7}$ in Fig. 6 (a), (b) and (c). Thus, the fault confidence level of $B_{14}$ is 0.5716 . Similarly, we obtain that the fault confidence level of $L_{0414}$ is 0.1805 .

Step 6: According to the fault condition, $B_{14}$ is a faulty section and $L_{0414}$ is not a faulty section. When bus $B_{14}$ has a fault, $C B_{1404}$ fails to trip while the second backup protective relays $L_{0414 S s}$ operates to trip $C B_{0414}$ to isolate this fault. Moreover, $L_{1415 R s}$ malfunctions in this case.

Case 2: line $L_{0414}$ has a fault.

Status information from the SCADA system: $\left(L_{0414 S m}, 27 \mathrm{~ms}\right),\left(L_{0414 R m}, 32 \mathrm{~ms}\right)$, (CB $\left.B_{0414}, 73 \mathrm{~ms}\right),\left(B_{14 m}, 91 \mathrm{~ms}\right),\left(L_{1415 R s}, 712 \mathrm{~ms}\right),\left(L_{1314 S s}, 736 \mathrm{~ms}\right),\left(C B_{1314}, 764 \mathrm{~ms}\right)$, $\left(C B_{1514}, 816 \mathrm{~ms}\right)$. 

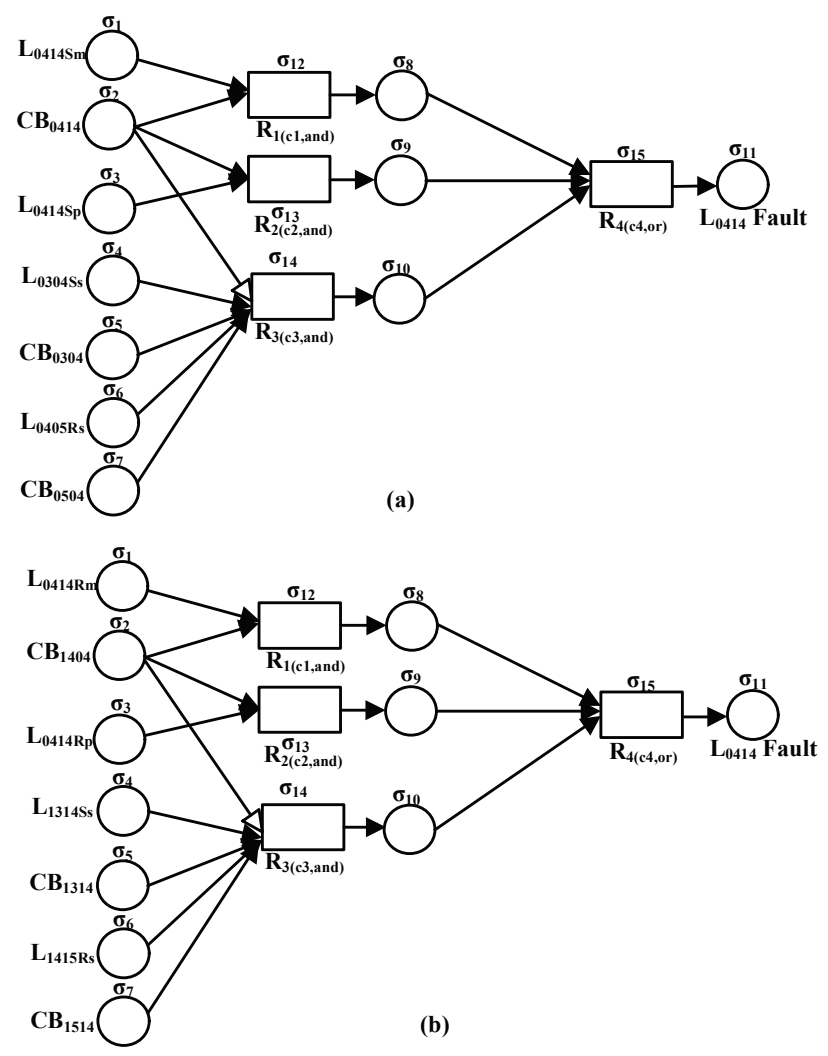

Fig. 7. Fault diagnosis models based on rTFRSN P systems for lien $L_{0414}$.

Results of handling temporal order information: $L=\left\{B_{14 m}\right\}, H=\left\{L_{0414 S m}\right.$, $\left.L_{0414 R m}, C B_{0414}, L_{1415 R s}, L_{1314 S s}, C B_{1314}, C B_{1514}\right\}$.

Diagnosis results: line $L_{0414}$ has a fault, and its fault confidence level is 0.6769 . We can see that when line $L_{0414}$ has a fault, $C B_{1404}$ fails to trip, and the second backup protective relays, $L_{1415 R s}$ and $L_{1314 S s}$, operate to trip $C B_{1514}$ and $C B_{1314}$ to isolate this fault. Moreover, $B_{14 m}$ maloperates in this case.

Case 3: line $L_{0414}$ has a fault.

Status information from the SCADA system: $\left(L_{0414 S m}, 21 \mathrm{~ms}\right),\left(C B_{0414}, 3 \mathrm{~ms}\right)$, ( $\left.L_{0414 R p}, 367 \mathrm{~ms}\right),\left(C B_{1404}, 370 \mathrm{~ms}\right)$.

Search for outage areas and find out candidate faulty sections by using network topology analysis. We find that there is only one candidate faulty section $L_{0414}$ in the passive network. According to subsection 4.2-Step 3, $L_{0414}$ is the faulty section. To verify the effectiveness of FDTSNP, we continue the rest of steps.

Results of handling temporal order information: $L=\varnothing, H=\left\{L_{0414 S m}, C B_{0414}\right.$, $\left.L_{0414 R p}, C B_{1404}\right\}$. 
Diagnosis results: line $L_{0414}$ has a fault, and its fault confidence level is 0.722 . We can see that when line $L_{0414}$ has a fault, its main protective relay $L_{0414 R m}$ rejects to operate while its first backup protective relays $L_{0414 R p}$ operates to trip $C B_{1404}$ to isolate this fault.

Case 4: bus $B_{14}$ and line $L_{0414}$ have faults.

Status information from the SCADA system: $\left(B_{14 m}, 25 \mathrm{~ms}\right),\left(L_{0414 S m}, 27 \mathrm{~ms}\right)$, ( $\left.L_{0414 R m}, 32 \mathrm{~ms}\right),\left(C B_{0414}, 62 \mathrm{~ms}\right),\left(C B_{1314}, 63 \mathrm{~ms}\right),\left(C B_{1404}, 75 \mathrm{~ms}\right),\left(C B_{1413}, 77 \mathrm{~ms}\right)$, ( $\left.L_{1415 R s}, 675 \mathrm{~ms}\right),\left(C B_{1514}, 816 \mathrm{~ms}\right)$.

Results of handling temporal order information: $L=\left\{C B_{1314}\right\}, H=\left\{B_{14 m}\right.$, $\left.L_{0414 S m}, L_{0414 R m}, C B_{0414}, C B_{1404}, C B_{1413}, L_{1415 R s}, C B_{1514}\right\}$.

Diagnosis resultsbus $B_{14}$ and Line $L_{0414}$ have faults, and their fault confidence levels are 0.707 and 0.7671 , respectively. We can see that bus $B_{14}$ and Line $L_{0414}$ have faults, $C B_{1415}$ fails to trip while the second backup protective relay $L_{1415 R s}$ operates to trip $C B_{1514}$ to isolate this fault. Moreover, $C B_{1314}$ maloperates in this case.

Case 5: lines $L_{0318}$ and $L_{0414}$ have faults.

Status information from the SCADA system: $\left(L_{0318 S m}, 34 \mathrm{~ms}\right),\left(L_{0318 R m}, 37 \mathrm{~ms}\right)$, ( $\left.C B_{0318}, 63 \mathrm{~ms}\right),\left(C B_{1817}, 132 \mathrm{~ms}\right),\left(L_{0414 S p}, 342 \mathrm{~ms}\right),\left(L_{0414 R p}, 350 \mathrm{~ms}\right),\left(C B_{0414}\right.$, $389 \mathrm{~ms}),\left(C B_{1404}, 391 \mathrm{~ms}\right),\left(L_{1718 R s}, 436 \mathrm{~ms}\right),\left(L_{1718 \mathrm{Ss}}, 712 \mathrm{~ms}\right),\left(C B_{1718}, 714 \mathrm{~ms}\right)$.

Results of handing temporal order information: $L=\left\{C B_{0318}, C B_{1817}\right\}, H=$ $\left\{L_{0318 S m}, L_{0318 R m}, L_{0414 S p}, L_{0414 R p}, C B_{0414}, C B_{1404}, L_{1718 R s}, L_{1718 S s}, C B_{1718}\right\}$.

Diagnosis Results: Lines $L_{0318}$ and $L_{0414}$ have faults, and their fault confidence levels are 0.5866 and 0.6769 , respectively. We can see that when line $L_{0318}$ has a fault, $C B_{1803}$ fails to trip while the second backup protective relay $L_{1718 S s}$ operates to trip $C B_{1718}$ to isolate the fault. And when line $L_{0414}$ has a fault, main protections $L_{0414 S m}$ and $L_{0414 R m}$ fail to operate while the first backup protective relays $L_{0414 S p}$ and $L_{0414 R p}$ operate to isolate the fault. More over, $L_{1718 R s}$ and $C B_{1817}$ maloperate in this case.

Table 2 lists the status information (alarm messages) from the SCADA system, candidate faulty sections and diagnosis results of these cases of FDTSNP (faulty sections, fault confidence levels and operation estimation), as well as comparisons between FDTSNP and three fault diagnosis methods, fuzzy Petri net (FPN), time sequence fuzzy Petri net (TSFPN) net and weighted fuzzy Petri net (WFPN), from [25], [26] and [27] respectively. It is worth pointing out that "-" means that this case was not considered in the corresponding reference and the diagnosis results of cases in Table 2 about FPN and TSFPT are listed in appendix $C$ of [27] rather than in [25] and [26].

From Table 2, we can see that diagnosis results of FDTSNP, from case 1 to case 5, are the same as those in [27]. In other words, FDTSNP is effective in fault diagnosis of electrical power systems. Table 2 also shows that in some cases, FDTSNP has superiority to FPN and TSFPN on correctly identifying fault sections. For instance, in case 4, the fault diagnosis results of FDTSNP are different from those of FPN and TSFPN. In this case, for section $L_{1415}$, only $L_{1415 R s}$ operated. Actually, $L_{1415 R s}$ operated as the second backup protective relay of section $B_{14}$ because of the operation failure of $C B_{1415}$. So in fact, $L_{1415}$ is not a faulty section. Thus, for case 4 , the diagnosis results of FDTSNP are better than those of FPN and TSFPN. Likewise, for case 5, the diagnosis results of FDTSNP are better than those of FPN and TSFPN. In cases 1-5, 
comparisons of diagnosis results verify that FDTSNP can obtain satisfying results in single and multiple fault situations with/without maloperation or operation failure of protective relays and CBs. Therefore, FDTSNP is effective with a good accuracy used in electrical power system fault diagnosis.

\section{Conclusions}

In this study, rTFRSN P systems are applied in fault diagnosis of power systems. A graphic modeling approach called FDTSNP, is presented for fault diagnosis of power systems. In FDTSNP, an rTFRSN P systems which can make use of temporal order information of alarm messages is introduced to model candidate fault sections, a reasoning algorithm of the rTFRSN P system is proposed for fault reasoning to obtain confidence levels of candidate faulty sections and temporal order information consistency constraint relationship is used to handle temporal order information of alarm messages from SCADA systems as well as judge its validity. Case studies show that FDTSNP is effective in fault diagnosis of power systems in different fault cases.

The ability of a fault diagnosis method is usually associated with knowledge availability and reasoning process. An rTFRSN P system is a novel graphic model with parallel computing ability for representing fuzzy knowledge and information, and different types of neurons increase the ways of knowledge representation and reasoning compared with traditional fault diagnosis tools. Since FDTSNP considers temporal order information of alarm messages which can correct alarm messages to handle the uncertainty and incompleteness in fault diagnosis without massive historical data collections and dependence on experts' experience, FDTSNP shows great potential in power system fault diagnosis and especially for complex or large-scale power grids. When a fault occurs in a power system, electrical quantities change firstly and then protective devices operate to isolate this fault. In this study, only alarm messages of protective devices are considered. In the future, we will pay attention to explore superiority of FDTSNP in fault diagnosis of complex or large-scale power systems and how to consider electrical measurements in the framework of FRSN P systems or SN P systems. Moreover, to test the speed and accuracy of rTFRSN P systems in fault diagnosis of power system, our future work will simulate them on MATLAB, P-Lingua and/or MeCoSim.

\section{Acknowledgment}

The work of K. Huang, T. Wang, Y. He and G. Zhang is supported by the National Natural Science Foundation of China (61170016, 61373047). The work of M.J. PérezJiménez is supported by Project TIN2012-37434 of the Ministerio de Economía y Competitividad of Spain.

\section{References}

1. Păun, Gh.: Computing with Membranes. Journal of Computer System Sciences 61(1), 108$143(2000)$ 
Table 2. Status information and comparisons between FDTSNP and three fault diagnosis methods

\begin{tabular}{|c|c|c|c|c|c|c|c|c|}
\hline \multirow[b]{2}{*}{ Cases } & \multirow{2}{*}{$\begin{array}{l}\text { Alarm } \\
\text { messages }\end{array}$} & \multirow{2}{*}{$\begin{array}{c}\text { Candidate } \\
\text { faulty sections }\end{array}$} & \multirow{2}{*}{$\begin{array}{l}\text { FPN } \\
{[25]}\end{array}$} & \multirow{2}{*}{$\begin{array}{c}\text { WFPN } \\
\text { [26] }\end{array}$} & \multirow{2}{*}{$\begin{array}{c}\text { TSFPN } \\
{[27]}\end{array}$} & \multicolumn{3}{|c|}{ diagnosis results of FDTSNP } \\
\hline & & & & & & $\begin{array}{c}\text { Faulty } \\
\text { sections }\end{array}$ & $\begin{array}{c}\text { Fault } \\
\text { confidence levels }\end{array}$ & $\begin{array}{l}\text { Operation } \\
\text { estimation }\end{array}$ \\
\hline 1 & $\begin{array}{c}\left(B_{14 m}, 20 \mathrm{~ms}\right) \\
\left(L_{0414 S s}, 750 \mathrm{~ms}\right) \\
\left(L_{1415 R s}, 371 \mathrm{~ms}\right) \\
\left(C B_{1415}, 73 \mathrm{~ms}\right) \\
\left(C B_{1413}, 81 \mathrm{~ms}\right) \\
\left(C B_{0414}, 87 \mathrm{~ms}\right)\end{array}$ & $\begin{array}{c}B_{14} \\
L_{0414}\end{array}$ & - & - & $B_{14}$ & $B_{14}$ & $\begin{array}{l}0.7671 \\
0.1805\end{array}$ & $\begin{array}{c}L_{1415 R s} \\
\text { maloperation } \\
C B_{1404} \\
\text { Operation failure }\end{array}$ \\
\hline 2 & $\begin{array}{c}\left(L_{0414 S m}, 27 \mathrm{~ms}\right) \\
\left(L_{0414 R m}, 32 \mathrm{~ms}\right) \\
\left(C B_{0414}, 73 \mathrm{~ms}\right) \\
\left(B_{14 m}, 91 \mathrm{~ms}\right) \\
\left(L_{1415 R s}, 712 \mathrm{~ms}\right) \\
\left(L_{1314 S s}, 736 \mathrm{~ms}\right) \\
\left(C B_{1314}, 764 \mathrm{~ms}\right) \\
\left(C B_{1514}, 816 \mathrm{~ms}\right)\end{array}$ & $\begin{array}{c}B_{14} \\
L_{0414} \\
L_{1415} \\
L_{1314}\end{array}$ & $\begin{array}{l}L_{0414} \\
L_{1415}\end{array}$ & $L_{0414}$ & $L_{0414}$ & $L_{0414}$ & $\begin{array}{l}0.1805 \\
0.7671 \\
0.1805 \\
0.1805\end{array}$ & $\begin{array}{c}B_{14 m}: \\
\text { maloperation } \\
C B_{1404}: \\
\text { operation failure }\end{array}$ \\
\hline 3 & $\left(\begin{array}{c}\left(L_{0414 S m}, 21 \mathrm{~ms}\right) \\
\left(C B_{0414}, 3 \mathrm{~ms}\right) \\
\left(L_{0414 R p}, 367 \mathrm{~ms}\right) \\
\left(C B_{1404}, 370 \mathrm{~ms}\right)\end{array}\right.$ & $L_{0414}$ & $L_{0414}$ & $L_{0414}$ & $L_{0414}$ & $L_{0414}$ & 0.7671 & $\begin{array}{c}L_{0414 R m}: \\
\text { operation failure }\end{array}$ \\
\hline 4 & $\begin{array}{c}\left(B_{14 m}, 25 \mathrm{~ms}\right) \\
\left(L_{0414 S m}, 27 \mathrm{~ms}\right) \\
\left(L_{0414 R m}, 32 \mathrm{~ms}\right) \\
\left(C B_{0414}, 62 \mathrm{~ms}\right) \\
\left(C B_{1314}, 63 \mathrm{~ms}\right) \\
\left(C B_{1404}, 75 \mathrm{~ms}\right) \\
\left(C B_{1413}, 77 \mathrm{~ms}\right) \\
\left(L_{1415 R s}, 675 \mathrm{~ms}\right) \\
\left(C B_{1514}, 816 \mathrm{~ms}\right)\end{array}$ & $\begin{array}{c}B_{14} \\
L_{0414} \\
L_{1314} \\
L_{1415}\end{array}$ & $\begin{array}{c}B_{14} \\
L_{0414} \\
L_{1415}\end{array}$ & $\begin{array}{c}B_{14} \\
L_{0414} \\
L_{1415}\end{array}$ & $\begin{array}{c}B_{14} \\
L_{0414}\end{array}$ & $\begin{array}{c}B_{14} \\
L_{0414}\end{array}$ & $\begin{array}{l}0.7671 \\
0.7671 \\
0.1805 \\
0.1805\end{array}$ & $\begin{array}{c}C B_{1314} \text { : } \\
\text { maloperation } \\
C B_{1415}: \\
\text { operation failure }\end{array}$ \\
\hline 5 & $\begin{array}{c}\left(L_{0318 S \mathrm{~m}}, 34 \mathrm{~ms}\right) \\
\left(L_{0318 R m}, 37 \mathrm{~ms}\right) \\
\left(C B_{0318}, 63 \mathrm{~ms}\right) \\
\left(C B_{1817}, 132 \mathrm{~ms}\right) \\
\left(L_{0414 S p}, 342 \mathrm{~ms}\right) \\
\left(L_{0414 R p}, 350 \mathrm{~ms}\right) \\
\left(C B_{0414}, 389 \mathrm{~ms}\right) \\
\left(C B_{1404}, 391 \mathrm{~ms}\right) \\
\left(L_{1718 R s}, 436 \mathrm{~ms}\right) \\
\left(L_{1718 S s}, 712 \mathrm{~ms}\right) \\
\left(C B_{1718}, 714 \mathrm{~ms}\right)\end{array}$ & $\begin{array}{c}B_{18} \\
L_{0318} \\
L_{1718} \\
L_{0414}\end{array}$ & $\begin{array}{c}B_{18} \\
L_{0318} \\
L_{1718} \\
L_{0414}\end{array}$ & $\begin{array}{c}B_{18} \\
L_{0318} \\
L_{0414}\end{array}$ & $\begin{array}{l}L_{0318} \\
L_{0414}\end{array}$ & $\begin{array}{l}L_{0318} \\
L_{0414}\end{array}$ & $\begin{array}{l}0.1805 \\
0.5866 \\
0.1805 \\
0.6769\end{array}$ & $\begin{array}{c}L_{1718 R s}, \\
C B_{1817} \\
\text { maloperation } \\
C B_{1803} \\
\text { operation failure }\end{array}$ \\
\hline
\end{tabular}


2. Ionescu, M., Păun, Gh., Yokomori, T.: Spiking Neural P Systems. Fundameta Informaticae 71(2-3), 279-308 (2006)

3. Păun, Gh., Pérez-Jiménez, M.J., Rozenberg, G.: Spike Trains in Spiking Neural P Systems. International Journal of Foundations of Computer Science, 17(4), 975-1002 (2006)

4. Păun, Gh., Rozenberg, G., Salomaa A: The Oxford Handbook of Membrance Computing. Oxford Unversity Press, New York (2010)

5. Pan, L.Q., Zeng, X.X.: Small Universal Spiking Neural P Systems Working in Exhaustive Mode. IEEE Transactions on Nanobioscience, 10(2), 99-105 (2011)

6. Song, T., Pan, L.Q., Păun, Gh.: Asynchronous Spiking Neural P Systems with Local Synchronization. Information Sciences 219, 197-207 (2013)

7. Chen, H., Ishdorj, T.O., Păun, Gh., Pérez-Jiménez, M.J.: Handling Languages with Spiking Neural P Systems With Extended Rules. Romanian Journal of Information Science and Technology, 9(3), 151-162 (2006)

8. Freund, R., Ionescu, M., Oswald, M.: Extended Spiking Neural P Systems with Decaying Spikes and/or Total Spiking. International Journal of Foundations of Computer Science, 19(5), 1223-1234 (2008)

9. Cavaliere, M., Ibarra, O.H., Păun, Gh., Egecioglu, O., Ionescu, M., Woodworth, S.: Asynchronous Spiking Neural P Systems. Theoretical Computer Science, 410(24-25), 2352-2364 (2009)

10. Pan, L.Q., Păun, Gh.: Spiking Neural P systems: An Improved Normal Form. Theoretical Computer Science, 411(6), 906-918 (2010)

11. Zhang, X.Y., Luo, B., Fang, X.Y., Pan, L.Q.: Sequential Spiking Neural P systems With Exhaustive Use of Rules. BioSystems, 108(1-3), 52-62 (2012)

12. Cabarle, F.G.C., Adorna, H.N., Martínez, M.A., Pérez-Jiménez, M.J.: Improving GPU Simulations of Spiking Neural P Systems. Romanian Journal of Information Science and Technology, 15(1), 5-20 (2012)

13. Cabarle, F.G.C., Adorna, H.N.: On Structures and Behaviors of Spiking Neural P Systems and Petri Nets. in: Proceeding of the 13th International Conference on Membrane Computing (CMC 2012), Budapest, Hungary, August 28-31, 2012, Revised Selected Papers. Lecture Notes in Computer Science, volume 7762, pp 145-160 (2012)

14. Peng, H., Wang, J., Pérez-Jiménez, M.J., Wang, H., Shao, J., Wang, T.: Fuzzy Reasoning Spiking Neural P System for Fault Diagnosis. Information Sciences 235(20), 106-116 (2013)

15. Xiong, G.J., Shi, D.Y., Zhu, L., Duan, X.Z.: A New Approach to Fault Diagnosis of Power Systems Using Fuzzy Reasoning Spiking Neural P Systems. Mathematical Problems in Engineering, 2013, Article ID 815352, 13 pages (2013)

16. Wang, J., Shi, P., Peng, H., Pérez-Jiménez, M.J., Wang, T.: Weighted Fuzzy Spiking Neural P Systems. IEEE Transactions on Fuzzy Systems 21(2), 209-220 (2013)

17. Tu, M., Wang, J., Peng, H., Shi, P.: Application of Adaptive Fuzzy Spiking Neural P systems in Fault Diagnosis of Power Systems. Chinese Journal of Electronics, 23(1), 87-92 (2014)

18. Wang, T., Zhang, G.X., Zhao, J.B., He, Z.Y., Wang, J., Pérez-Jiménez, M.J.: Fault Diagnosis of Electric Power Systems Based on Fuzzy Reasoning Spiking Neural P Systems. IEEE Transactions on Power Systems, 30(3), 1182-1194 (2015)

19. Wang, T., Zhang, G.X., Rong, H.N., Pérez-Jiménez, M.J.: Application of Fuzzy Reasoning Spiking Neural P Systems to Fault Diagnosis. International Journal of Computers, Communications and Control, 9(6), 786-799 (2014)

20. Wang, T., Zhang G.X., Pérez-Jiménez, M.J., Cheng, J.X.: Weighted Fuzzy Reasoning Spiking Neural P Systems: Application to Fault Diagnosis in Traction Power Supply Systems of High-Speed Railways. Journal of Computational and Theoretical Nanoscience, 12(7), 1103 $1114(2015)$ 
21. Wang, T., Zhang G.X., Pérez-Jiménez, M.J.: Fuzzy Membrane Computing: Theory and Appliacations. International Journal of Computers, Communications and Control, 10(6), 861-892 (2015)

22. Zhang, G. X., Rong, H.N., Neri, F., Pérez-Jiménez, M.J.: An Optimization Spiking Neural P system for Approximately Solving Combinatorial Optimization Problems. International Journal of Neural Systems, 24(5), 1440006 (16 pages) (2014)

23. Guo, W.X., Wen, F.S., Liao, Z.W.: An Analytic Model for Power System Online Alarm Processing Based on Temporal Constraint Network. Automation of Electric Power Systems, 33(21), 36-42 (2009)

24. Zhang, Y., Zhang, Y., Wen F.S.: A Temporal Cause-Effect Net Based Approach for Power System Fault Diagnosis. Automation of Electric Power Systems, 37(9), 47-53 (2013)

25. Sun, J., Qin, S.Y., Song, Y.H.: Fault Diagnosis of Electric Power System Based on Fuzzy Petri Nets. IEEE Transactions on Power Systems, 19(4), 2053-2059 (2004)

26. Yang, J.W., He Z.Y.: Power System Fault Diagnosis Approach Based on Time Sequence Fuzzy Petri Net. Automation of Electric Power Systems, 35(15), 46-51 (2011)

27. Wu, W.K., Wen, F.S.: A Weighted Fuzzy Petri Net Based Model with Time-Delay Constraints for Power Systems Fault Diagnosis Employing Information From Multiple Sources. Automation of Electric Power Systems, 37(24), 43-53 (2013) 